\title{
Assessing the usefulness of clostridia spores for evaluating sewage sludge hygienization
}

\author{
Julia Martín-Díaz ${ }^{\mathrm{a}, \mathrm{b}, *}$, Maria Ruiz-Hernando ${ }^{\mathrm{c}}$, Sergi Astals ${ }^{\mathrm{c}, \mathrm{d}}$, Francisco Lucena ${ }^{\mathrm{a}, \mathrm{b}}$
}

${ }^{a}$ Department of Genetics, Microbiology and Statistics, University of Barcelona, Av. Diagonal 643, 08028

Barcelona, Spain

${ }^{\mathrm{b}}$ The Water Research Institute, University of Barcelona, C/ Montalegre 6, 08001 Barcelona, Spain

${ }^{c}$ Department of Chemical Engineering, University of Barcelona, C/ Martí i Franquès 1, 6th floor, 08028

Barcelona, Spain.

dAdvanced Water Management Centre, The University of Queensland, St Lucia, QLD 4072, Australia

*Corresponding author: Tel.: +34 934021484; fax: +34 934110592. E-mail address:

juliamadi@hotmail.com (J. Martín-Díaz). 


\begin{abstract}
The capability of clostridia spores to act as pathogen indicators in sewage sludge treatment was investigated. Sulfite-reducing clostridia and E. coli levels were monitored during waste activated sludge pre-treatments (alkali and ultrasound) and its subsequent mesophilic anaerobic digestion. E. coli was maintained or reduced depending on treatment type and intensity. However, alkali pre-treatment (35.3 $\mathrm{gNaOH} / \mathrm{kg}$ TS $)$ by itself and alkali (157 $\mathrm{gNaOH} / \mathrm{kg} \mathrm{TS})$ and ultrasound $(27,000 \mathrm{~kJ} / \mathrm{kg} \mathrm{TS})$ pre-treatments followed by anaerobic digestion provoked reproducible clostridia increases. Specifically, up to $2.7 \log _{10}$ after $35.3 \mathrm{gNaOH} / \mathrm{kg}$ TS pre-treatment and up to 1.9 and $1.1 \log _{10}$ after digesting the $157 \mathrm{gNaOH} / \mathrm{kg}$ TS and $27,000 \mathrm{~kJ} / \mathrm{kg}$ TS pre-treated sludge, respectively. Having rejected the hypotheses of sporulation and floc dissipation, the most plausible explanation for these clostridia increases is re-growth. These results question the suitability of clostridia spores as indicators of sludge treatment and other biological treatments where clostridia may have a role.
\end{abstract}

\title{
Keywords
}

Clostridium spores, Anaerobic digestion, Sewage sludge, Hygienization treatment, Indicator.

\section{Introduction}

Ever more solutions are being used worldwide to manage the sewage sludge produced in wastewater treatment plants (WWTPs), including biological, mechanical, thermal and chemical treatments, and a combination of these. Treatment processes convert sewage sludge into biosolids, a stabilized product suitable for beneficial use. However, due to the high levels of pathogens naturally present in sludge (Guzmán et al., 2007; Lepeuple 
et al., 2004), only some treatments (or more specifically, only some treatment conditions) guarantee the safe levels required for use of biosolids as fertilizer, the preferred management option. In this context, the use of indicator microorganisms is an excellent tool to evaluate the microbiological risk associated with these practices, since they can indicate the hygienization capacity of treatment processes. Current regulations and regulation proposals already include some pathogens (e.g. Salmonella, enteric viruses) and/or indicator microorganisms (e.g. Escherichia coli, fecal coliforms) to assess sludge microbiological quality (European Commission, 2000; The Council of European Communities, 1986; US Environmental Protection Agency, 2003). However, conventional fecal indicator bacteria such as Escherichia coli (E. coli) or Enterococcus are not suitable to determine the behavior of pathogens that are highly resistant to intensive treatment processes, such as protozoa oocysts or helminth ova. To overcome these limitations, the spores of sulfite-reducing clostridia (SSRC) have been proposed and used for years as alternative indicators in water treatment processes (AgullóBarceló et al., 2013; Hill and Sobsey, 1998; Lepeuple et al., 2004; Marti et al., 2011; Payment and Franco, 1993). The use of SSRC as indicators in sludge has several advantages: (i) they are present in large numbers, (ii) they exhibit high resistance to intensive treatments, and (iii) ther are easy, rapid and standardized detection methods (Guzmán et al., 2007; Lepeuple et al., 2004; Warnes and Keevil, 2004). Nonetheless, they can exhibit excessive resistance to treatment (Lepeuple et al., 2004) and concentrations may even increase after treatment (Rainisalo et al., 2011; Ruiz-Hernando et al., 2014; Salsali et al., 2008). This latter is a major drawback and calls into question the suitability of clostridia spores as indicators in sewage sludge treatment, since concentration increases are not expected for the pathogens they are indicating, i.e., protozoa oocysts and helminth ova. The nature of these unexpected increases has not yet 
been studied in depth and it still remains unknown whether they are due to reactivation, sporulation processes, re-growth or some other cause. Conversely, the reactivation of $E$. coli from a viable but non culturable state in response to certain treatments is wellknown (Erkan and Sanin, 2013; Pascual-Benito et al., 2015).

Anaerobic digestion (AD) is one of the most common sewage sludge treatment processes at WWTPs, since it degrades organic matter, produces energy in the form of methane and kills pathogens. A mixture of primary sludge and waste activated sludge (WAS) is typically fed to WWTP anaerobic digesters. However, WAS has a relatively low biodegradability due to its microbial biomass and extracellular polymeric substances (EPSs) composition (Carrere et al., 2016; Ruiz-Hernando et al., 2015). The introduction of pre-treatments before $\mathrm{AD}$ can be used to improve WAS biodegradability. Moreover, these treatments may act on pathogens and may even be used as post-treatments after AD to achieve sludge hygienization (Astals et al., 2012).

Ruiz-Hernando et al. (2014) assessed the hygienization capacity of ultrasound, lowtemperature thermal and alkali treatments on WAS and their combination as mesophilic $\mathrm{AD}$ pre- or post-treatments. During these processes, bacterial and bacteriophage indicators were monitored (i.e., E. coli, somatic coliphages and SSRC). Although E. coli was the most sensitive microorganism, apparently being suitable to indicate enteric bacteria, alkali treatment increased $E$. coli levels under one of the specific conditions assayed (35.3 $\mathrm{g} \mathrm{NaOH} / \mathrm{kg} \mathrm{TS})$. Similarly, although SSRC were the most resistant microorganisms, apparently being suitable to indicate protozoa oocysts and helminth ova, unexpected results were obtained under several of the conditions assayed. Specifically, high increases in SSRC levels were observed (i) during alkali pre- 
treatment (35.3 g NaOH/kg TS), (ii) after mesophilic AD of alkali pre-treated WAS (157 $\mathrm{g} \mathrm{NaOH} / \mathrm{kg} \mathrm{TS})$ and (iii) after mesophilic AD of ultrasound pre-treated sludge $(27,000 \mathrm{~kJ} / \mathrm{kg} \mathrm{TS})$.

The aim of the present research was to further investigate the results obtained in the previous study (Ruiz-Hernando et al., 2014) and to conduct an in-depth assessment of the capacity of SSRC to act as indicators in sewage sludge treatments. To this end, all the treatments and conditions involved were repeated and carefully examined. The concentrations of E. coli, SSRC and total culturable cells of sulfite-reducing clostridia (TSRC) were closely monitored. Additionally, data for these indicators were obtained from raw wastewater, human feces and sludge samples.

\section{Materials and methods}

\subsection{Sludge and wastewater origin}

Sludge samples were taken from two municipal WWTPs $\left(\mathrm{WWTP}_{1}\right.$ and $\left.\mathrm{WWTP}_{2}\right)$ in the Barcelona metropolitan area (Spain). $\mathrm{WWTP}_{1}$ treats about 420,000 $\mathrm{m}^{3}$ wastewater/day and serves a population of 2,275,000 equivalent inhabitants. At $\mathrm{WWTP}_{1}$, WAS is thickened by centrifugation after leaving the secondary tank. Afterwards, a mixture of $50 \%$ primary sludge and $50 \%$ WAS is subjected to mesophilic AD with a hydraulic retention time of 37-42 days. $\mathrm{WWTP}_{2}$ has a treatment capacity of $64,000 \mathrm{~m}^{3}$ wastewater/day and serves a population of 385,000 equivalent inhabitants. At $\mathrm{WWTP}_{2}$, a mixture of $60 \%$ primary sludge and $40 \%$ WAS is anaerobically digested under mesophilic conditions with a hydraulic retention time of 20-24 days. The WAS samples used in this study were collected from $\mathrm{WWTP}_{1}$, whereas the digested sludge used as inoculum came from $\mathrm{WWTP}_{2}$. The total solids (TS) content of the WAS samples was 
$54.9 \pm 11.6 \mathrm{~g} / \mathrm{L}$ (mean \pm standard deviation). The TS content of the inoculum sample was $23.1 \mathrm{~g} / \mathrm{L}$. In addition, sludge samples were taken from both WWTPs before and after AD, as well as raw wastewater. The TS and volatile solids were determined following the guidelines given by the standard methods 2540G (APHA, 2005).

\subsection{Human feces origin}

Two human feces samples were collected from healthy individuals to evaluate the sulfite-reducing clostridia and E. coli concentrations typically present in these types of sample. The TS content was calculated as described in Section 2.1 and was $275.7 \pm 15.8$ $\mathrm{g} / \mathrm{L}$ (mean \pm standard deviation).

\subsection{Pre-treatment conditions}

The pre-treatments studied in this research were ultrasound and alkali. The ultrasonic apparatus used was an HD2070 Sonopuls Ultrasonic Homogenizer equipped with a MS 73 titanium microtip probe (Bandelin, Berlin, Germany; $20 \mathrm{kHz}$ ). The beaker containing the samples was submerged in an ice bath to prevent an increase in sludge temperature due to the thermal effect of the cavitation phenomenon. The specific energies $\left(E_{S}\right)$ applied were $27,000,40,000$ and 60,000 kJ/kg TS (named as 27,000-US, 40,000-US and 60,000-US, respectively). $\mathrm{E}_{\mathrm{S}}$ were calculated as follows:

$$
\mathrm{E}_{\mathrm{S}}=\frac{\mathrm{P} \cdot \mathrm{t}}{\mathrm{V} \cdot \mathrm{TS}}
$$

where $P$ is the ultrasonic power of the ultrasonic homogenizer $(\mathrm{kW}), t$ is the application time (s), $V$ is the sample volume (L) and $T S$ is the concentration of total solids $(\mathrm{g} / \mathrm{L})$. 
The alkali pre-treatment was conducted at room temperature (approximately $25^{\circ} \mathrm{C}$ ) by adding different doses of $\mathrm{NaOH}$ with a contact time of $24 \mathrm{~h}$. Samples were subsequently neutralized with $\mathrm{HCl}_{35 \%}$ to reach a $\mathrm{pH}$ range of 6.5-7.5. The concentrations studied were 35.3 and $157 \mathrm{~g} \mathrm{NaOH} / \mathrm{kg}$ TS (named 35.3-NaOH and 157- $\mathrm{NaOH}$, respectively).

Another alkali pre-treatment was conducted using a glycine buffer to isolate the effect of $\mathrm{pH}$ (named GLY). The glycine buffer $(0.25 \mathrm{M}, \mathrm{pH} 10.5)$ was prepared and $10 \mathrm{~g}$ of the WAS samples was diluted in a 1:10 (W/V) ratio with this buffer. Samples were then periodically acidified through the addition of $\mathrm{HCl}_{35 \%}$ during the $24 \mathrm{~h}$ treatment, with the aim of reproducing the $\mathrm{pH}$ drop in the $35.3-\mathrm{NaOH}$ pre-treatment. Untreated sludge was monitored and used as control.

\subsection{Mesophilic anaerobic digestion}

AD was evaluated through biomethane potential (BMP) tests carried out under mesophilic conditions using batch tests. The procedure was the same as that described in a previous study (Ruiz-Hernando et al., 2014). Briefly, the BMP tests were performed in $115 \mathrm{~mL}$ serum bottles sealed with a PTFE/butyl septum, which was fixed by an aluminum crimp cap. The bottles were filled with $50 \mathrm{~mL}$ of inoculum and $8.7 \mathrm{~mL}$ of WAS sample (untreated or treated), which met an inoculum to substrate ratio of 2 in volatile solid basis considering the untreated WAS volatile solid value (52.7 $\mathrm{g} \mathrm{VS} / \mathrm{L})$. Before sealing the bottles, all digesters were flushed with nitrogen for 1 minute (3 $\mathrm{L} / \mathrm{min}$ ). Finally, digesters were placed in a water bath at $37 \pm 1^{\circ} \mathrm{C}$. The bottles were manually mixed by swirling twice a day. Digestion lasted 35 days and samples were taken at the beginning, after 15 days and at the end of the treatment. 


\subsection{Detection and enumeration of $E$. coli and sulfite-reducing clostridia}

Five to ten grams of sludge was mixed in a 1:10 (W/V) ratio with phosphate buffered saline (PBS) pH 7.2, homogenized with a wrist action shaker at $900 \mathrm{osc} / \mathrm{min}$ for $30 \mathrm{~min}$ at room temperature and then centrifuged at $300 \times \mathrm{g}$ for $3 \mathrm{~min}$ at $4{ }^{\circ} \mathrm{C}$. The resulting supernatant was used to analyze the E. coli and sulfite-reducing clostridia present in the sample. For E. coli, samples were cultured in Chromocult agar plates (Merck, Germany) supplemented with E. coli/coliform-selective supplement (Merck, Germany) using the pour plate procedure. Plates were incubated at $44^{\circ} \mathrm{C}$ overnight, and dark-blue/purple $E$. coli colonies were counted. For sulfite-reducing clostridia, TSRC were directly tested from the supernatant, while SSRC were tested after subjecting the supernatant to a thermal shock of $80^{\circ} \mathrm{C}$ for $10 \mathrm{~min}$. Clostridia were cultured by mass inoculation in Clostridium perfringens selective agar (Scharlab, Spain), followed by incubation in anaerobic conditions at $44{ }^{\circ} \mathrm{C}$ overnight. The typical black spherical colonies were counted as clostridia. According to the manufacturer's instructions, about $90 \%$ of the colonies can be attributed to $C$. perfringens. Since no confirmation of results was conducted, the colonies obtained were counted as sulfite-reducing clostridia.

\subsection{Experimental design}

The initial stage of the study aimed to assess the impact of different pre-treatments on microbial indicators. First, the pre-treatment conditions from Ruiz-Hernando et al. (2014) that produced unexpected results by themselves or in combination with AD, were repeated to confirm data. They were $35.3-\mathrm{NaOH}, 157-\mathrm{NaOH}$ and $27,000-\mathrm{US}$. Second, 35.3- $\mathrm{NaOH}$ was studied in greater depth and a complementary alkali strategy, GLY, was applied to isolate the effect of $\mathrm{pH}$. Later on, two more ultrasound pre- 
treatment conditions were tested, i.e., 40,000-US and 60,000-US. In a second stage, untreated and pre-treated WAS samples were subjected to mesophilic AD to confirm Ruiz-Hernando et al. (2014) results. In the final stage, the study was complemented with (i) data from the WWTPs: raw wastewater and sewage sludge before and after mesophilic AD and (ii) data from human feces. All samples assayed in this study were tested in duplicate and the means and standard deviations were calculated. Fresh samples were collected for each experiment.

\section{Results and discussion}

\subsection{Impact of pre-treatments on indicators}

The unexpected clostridia increases obtained in Ruiz-Hernando et al. (2014) may suggest a sporulation process in response to adverse conditions. In this scenario, vegetative clostridia cells would have transformed into the resistant form (spores) thus increasing the number of SSRC detected. To test this hypothesis, the pre-treatments involved were repeated and TSRC were monitored together with SSRC.

As shown in Fig. 1, it was found an increase of $2.73 \log _{10}$ (CFU/g TS) in TSRC levels and $1.78 \log _{10}$ in SSRC levels for 35.3-NaOH as compared with untreated sludge. The $\mathrm{pH}$ at the beginning of this pre-treatment reached 10.3 , however, the buffer capacity of the sludge itself steadily reduced the $\mathrm{pH}$ to 7.0 after $24 \mathrm{~h}$. Consequently, it was not necessary to add $\mathrm{HCl}_{35 \%}$ for neutralization. Contrariwise, for $157-\mathrm{NaOH}$, where the $\mathrm{pH}$ rose to more than 12 and it maintained for $24 \mathrm{~h}$, both clostridia populations were similarly reduced, i.e., $1.61 \log _{10}$ for TSRC and $1.63 \log _{10}$ for SSRC. A smaller effect was observed for 27,000-US, with increases of 0.33 and $0.28 \log _{10}$ for TSRC and SSRC respectively, in comparison with the untreated sludge. These results were similar to 
those obtained in the previous study, confirming their reproducibility for the pretreatment conditions assayed. Furthermore, it is important to highlight the simultaneous increase in both spores and total cultivable cells, suggesting that the effect of sporulation alone is insufficient to explain the increase in clostridia levels.

Due to the notable increases observed in clostridia (TSRC and SSRC) after 35.3-NaOH pre-treatment in Ruiz-Hernando et al. (2014) and in the present study, this pre-treatment was repeated and further analyzed by monitoring $\mathrm{pH}$ and microbial concentrations during the $24 \mathrm{~h}$ of treatment contact time. Results are presented in Fig. 2. For the untreated WAS, the pH varied between 6.67 and 6.37 and sulfite-reducing clostridia levels were maintained. Specifically, mean values of $6.12 \pm 0.16$ and $6.09 \pm 0.17 \log _{10}$ (CFU/g TS) were obtained for TSRC and SSRC, respectively. For the alkali pre-treated sample, the initial $\mathrm{pH}$ value was 10.4 , which decreased to 6.92 after $24 \mathrm{~h}$. Regarding $E$. coli, no effect was observed this time after treating the sample and concentrations were maintained from $5.72 \pm 0.05$ to $5.79 \pm 0.02 \log _{10}(\mathrm{CFU} / \mathrm{g} \mathrm{TS})$ for the untreated sample and from $5.80 \pm 0.01$ to $5.96 \pm 0.01$ for the $35.3-\mathrm{NaOH}$ sample. Thus, it appeared that the increase observed for this bacterium in the previous study (Ruiz-Hernando et al., 2014) was not a reproducible outcome. Contrarily, a considerable increase in sulfitereducing clostridia levels was observed for the 35.3-NaOH sample, resulting in 1.29 $\log _{10}$ for TSRC and $0.77 \log _{10}$ for SSRC. These increases took place during the mid to late phase of the treatment. Under optimal nutrient, temperature and $\mathrm{pH}$ conditions, reported doubling times for some Clostridium species are below 10 minutes (Labbe and Huang, 1995; McClane, 2003). In addition, a previous study has shown that alkali treatment of WAS induces carbohydrate and protein solubilization together with volatile fatty acids formation (Chen et al., 2007). Thus, 35.3-NaOH may have provided 
clostridia with these products during the initial phases of the pre-treatment and clostridia could have used them to grow during the mid to late phase, when the $\mathrm{pH}$ was favorable. Contrarily, the higher $\mathrm{pH}$ during $157-\mathrm{NaOH}$ may have prevented clostridia re-growth under these pre-treatment conditions and the pre-treatment was so intense that reduced its concentrations (Fig. 1). However, re-growth may not be the only explanation for this increase in clostridia levels. It is widely known that colony forming unit (CFU) counts increase when cell flocs in a sample are dissipated. These flocs, which are naturally found in the sludge matrix, contain bacterial aggregates that are counted as a single CFU; thus masking the real cultivable bacteria numbers. Since floc dissipation may occur due to $\mathrm{pH}$ changes and sonication, the hypothesis of floc dissipation was launched.

The effect of $\mathrm{pH}$ on SSRC was tested through an alkali treatment using a glycine buffer (GLY) instead of $\mathrm{NaOH}$. As shown in Table 1, the $\mathrm{pH}$ curve for 35.3-NaOH was satisfactorily reproduced. However, in this case, no differences in clostridia levels were found when comparing the untreated and the GLY-treated samples. Specifically, SSRC concentrations varied from $7.01 \pm 0.02$ to $7.14 \pm 0.03 \log _{10}(\mathrm{CFU} / \mathrm{g}$ TS $)$ for the untreated sample and from $6.87 \pm 0.09$ to $6.94 \pm 0.04 \log _{10}$ (CFU/g TS) for the GLY sample. Accordingly, the posited floc dissipation did not occur. From this experiment, it may be concluded that $\mathrm{pH}$ is not the causal agent of clostridia increases or, at least, it is not the only factor implicated. It is conceivable that the reagents and conditions used to cause this $\mathrm{pH}$ trend were also important factors. To determine the impact of sonication on CFU counts WAS samples were subjected to more intense ultrasound treatments, specifically to $40,000-\mathrm{US}$ and 60,000 -US. The aim was to increase treatment intensity to such an extent that it produced floc dissipation and a consequent increase in clostridia 
and E. coli counts (Foladori et al., 2007). The results are shown in Fig. 3. Neither the 40,000-US nor the 60,000-US treatment produced increases in TSRC or SSRC levels. Nevertheless, these treatments were sufficiently intense to produce $E$. coli death, resulting in decreases of 0.77 and $1.35 \log _{10}$ for $40,000-\mathrm{US}$ and $60,000-\mathrm{US}$, respectively.

\subsection{Impact of mesophilic anaerobic digestion on indicators}

To analyze sulfite-reducing clostridia (TSRC and SSRC) behavior during mesophilic AD a new WAS sample was pre-treated, i.e., 35.3- $\mathrm{NaOH}, 157-\mathrm{NaOH}$ and 27,000-US. Then, $8.7 \mathrm{~mL}$ of untreated or pre-treated WAS were mixed with $50 \mathrm{~mL}$ of inoculum. The larger volume and the higher sulfite-reducing clostridia concentrations $(7.07 \pm 0.17$ $\log _{10}$ of TSRC/g TS and $7.17 \pm 0.04 \log _{10}$ of SSRC/g TS) made inoculum the major contributor of sulfite-reducing clostridia in the digestion media (Fig. 4). This contribution can be observed comparing the untreated samples in Fig. 1 and Fig. 4. After 35 days of digestion, TSRC and SSRC levels in the untreated and 35.3-NaOHtreated samples remained similar to the beginning, while $157-\mathrm{NaOH}$ and $27,000-\mathrm{US}$ resulted in TSRC and SSRC increases. These increments in sulfite-reducing clostridia were already visible after 15 days and more remarkable after 35 days of digestion (Fig. 4). For 157-NaOH, TSRC concentrations increased by $1.97 \log _{10}$ and SSRC by 1.45 $\log _{10}$, while for 27,000 -US, TSRC concentrations increased by $1.16 \log _{10}$ and SSRC by

$0.49 \log _{10}$. These results are similar to those obtained in Ruiz-Hernando et al. (2014) and confirm that the combination of some pre-treatments (or more specifically, some pre-treatment conditions) followed by digestion increase clostridia numbers. These increases in TSRC and SSRC concentrations cannot be linked to $\mathrm{pH}$ changes since $\mathrm{pH}$ remained constant $(7.13-7.41)$ throughout the entire digestion process. The paragraphs 
that follow consider a number of possible explanations for the unexpected sulfitereducing clostridia behavior, and conclude with a plausible hypothesis.

Pre-treatments kill sulfite-reducing clostridia competitors in WAS favoring them numerically.

The sludge cell disruption and solubilization is a well-known phenomenon for most WAS pre-treatments (Carrere et al., 2016). Therefore, it can be expected that pretreatments could have impacted on some WAS bacterial populations in a greater extent than sulfite-reducing clostridia, favoring them numerically when mixed with inoculum. This hypothesis implies that the contribution of WAS to the active biomass in a BMP test is relevant. However, the inoculum contribution to clostridia abundance in the digestion media was 1,000 and 10 times higher than the $157-\mathrm{NaOH}$ and 27,000-US pretreated WAS contribution, respectively. Furthermore, this hypothesis cannot explain the sulfite-reducing clostridia increases reported after digesting 27,000-US-treated WAS. In Ruiz-Hernando et al. (2014) this pre-treatment condition did not kill SSRC, E. coli or somatic coliphages; and therefore it is unlikely that it disrupted other bacteria.

Sulfite-reducing clostridia use soluble compounds and cell debris released during WAS pre-treatments to grow during digestion.

The visualization of TSRC and SSRC levels increasing under favorable $\mathrm{pH}$ conditions during the 35.3- $\mathrm{NaOH}$ pre-treatment (see Section 3.1) gave rise to the hypothesis that sulfite-reducing clostridia from the $157-\mathrm{NaOH}$ sample could have increased during digestion as a result of the better $\mathrm{pH}$ conditions and the large amount of easily biodegradable compounds. Recent studies using molecular techniques have revealed the 
multifaceted role of Clostridium on $\mathrm{AD}$, which can take part of most $\mathrm{AD}$ steps prior to methanogenesis (i.e., hydrolysis, acidogenesis, acetogenesis and acetate-oxidation) (Shah et al., 2014; Stiborova et al., 2015; Tian et al., 2015; Yuan et al., 2015). Interestingly, Jang et al. (2014) and Park et al. (2014) reported the growth of some groups of Clostridium after subjecting thermal and alkali pre-treated sludge to mesophilic AD. The presence of easily biodegradable compounds may have also favored sulfite-reducing clostridia re-growth during digestion of 27,000-US-treated WAS. The presence of easily biodegradable compounds should have also favored sulfite-reducing clostridia re-growth during sonication (27,000-US); however, this may have not been observed due to the short treatment time (7-8 minutes depending on sample TS). Nonetheless, this hypothesis cannot explain why in Ruiz-Hernando et al. (2014) sulfite-reducing clostridia did not grow after digesting low-temperature pretreated WAS $\left(80^{\circ} \mathrm{C}\right.$ and $15 \mathrm{~min}$ ); sample that showed similar solubilization degrees than $157-\mathrm{NaOH}$ and $27,000-\mathrm{US}$.

Pre-treatment derived inhibitory compounds promote sulfite-reducing clostridia regrowth over other bacteria.

The last hypothesis is related to the presence of inhibitory compounds in the digestion media from WAS pre-treatments, which could have favored sulfite-reducing clostridia re-growth over other anaerobic bacteria. In this scenario, the $\mathrm{Na}^{+}$introduced during the alkali pre-treatments or the inhibitory compounds generated during sonication (Peces et al., 2015) could have favored sulfite-reducing clostridia re-growth by limiting the growth of other bacteria. However, the addition of $157 \mathrm{~g} \mathrm{NaOH} / \mathrm{g} \mathrm{TS}$ only represents an extra load of $0.74 \mathrm{~g} \mathrm{Na}^{+} / \mathrm{L}$, giving a final digestion media concentration of $1 \mathrm{~g} \mathrm{Na}^{+} / \mathrm{L}$ when mixed with the inoculum. This $\mathrm{Na}^{+}$concentration is known as not inhibitory for 
acetoclastic methanogens and therefore, even less likely to be inhibitory for bacteria (Astals et al., 2015). Indeed, in Ruiz-Hernando et al. (2014) no inhibition (rate and extent) was observed during 157- $\mathrm{NaOH}$ and 27,000-US BMP testing. However, a change in bacteria populations caused by the presence of inhibitors cannot be detected by this technique. This hypothesis can explain why in Ruiz-Hernando et al. (2014) no sulfite-reducing clostridia re-growth was observed after low-temperature pre-treated (80 ${ }^{\circ} \mathrm{C}$ and $15 \mathrm{~min}$ ) WAS digestion; since this pre-treatment conditions do not generate inhibitory compounds (Carrere et al., 2016; Carrère et al., 2010).

Overall, it is likely that sulfite-reducing clostridia increased during digestion as a response to favorable conditions generated by the pre-treatments assayed. Although it is not completely clear which are the dominating mechanisms behind TSRC and SSRC increases, results seem to indicate that re-growth is the most plausible explanation. However, reactivation from a viable but non culturable state cannot be completely discarded.

\subsection{Sulfite-reducing clostridia and $E$. coli behavior in the wastewater treatment} process

TSRC, SSRC and E. coli levels found in human feces and during the wastewater treatment process conducted at two full-scale WWTPs are shown in Table 2. The findings obtained do not expect to be an exhaustive analysis of the microbial concentrations present in the different samples studied, since the number of samples was limited. However, they can be useful to reflect the general assumed behavior of sulfite-reducing clostridia and E. coli during the wastewater treatment process. E. coli is a non-conservative indicator with low resistance to treatment, whereas SSRC are 
conservative, capable of resisting high intensity treatments. E. coli concentrations in fresh human feces greatly exceeded sulfite-reducing clostridia levels and similar results were found in wastewater. As treatment progressed, clostridia concentrations were maintained due to their higher resistance, whereas E. coli levels dropped. A calculation of the SSRC/E. coli ratio clearly reflects this tendency. After AD, clostridia concentrations in sludge were significantly higher than those for E. coli. Wéry et al. (2008) found a similar trend throughout wastewater treatment processes, including composting.

As shown in Fig. 4, sulfite-reducing clostridia levels did not increase when the digesters were fed with untreated WAS. Likewise, a study of AD routinely performed at the two WWTPs (Table 2), where the sludge is not pre-treated to enhance digestion, revealed a similar behavior. This agrees with previous studies (Bagge et al., 2005; Guzmán et al., 2007; Sahlström et al., 2004) and suggests that sulfite-reducing clostridia and E. coli populations are not generally increased by the effect of $\mathrm{AD}$ alone.

Taken together, the findings of this study confirm that some pre-treatments or combinations of pre-treatments followed by AD led to increases in sulfite-reducing clostridia from WAS. Further studies including the use of a molecular method, such as qPCR, would clarify whether these increases are due to re-growth, reactivation or simple increases in colony counts. Nevertheless, the hypotheses of sporulation and floc dissipation have been rejected. Other authors have found similar increases in $C$. perfringens or sulfite-reducing clostridia during storage of composted mixtures of sludge and plant wastes (Rainisalo et al., 2011) or in digested sludge subjected to different temperatures, volatile fatty acid concentrations and pHs (Salsali et al., 2008). 
In addition, recent studies (Shah et al., 2014; Stiborova et al., 2015; Tian et al., 2015; Yuan et al., 2015) have revealed the Clostridium multifaceted role in AD. All this information suggests that the use of SSRC or C. perfringens spores as indicators of protozoa oocysts and helminth ova may not be the most suitable choice for sewage sludge samples subjected to $\mathrm{AD}$, since the indicator behavior does not reflect the pathogen behavior.

\section{Conclusions}

The capability of clostridia spores to act as pathogen indicators in sewage sludge treatment was examined. Sulfite-reducing clostridia (spores and culturable cells) and $E$. coli were monitored in waste activated sludge subjected to alkali and ultrasound pretreatments and their combination with mesophilic anaerobic digestion. Some treatment conditions reduced E. coli. However, alkali pre-treatment (35.3- $\mathrm{NaOH})$ and alkali and ultrasound pre-treatments (157-NaOH; 27,000-US) followed by anaerobic digestion repeatedly increased clostridia. Having rejected sporulation and floc dissipation, the most plausible explanation is re-growth. Considering the multifaceted role of Clostridium in anaerobic digestion, results question the suitability of clostridia spores as sludge treatment indicators.

\section{Acknowledgments}

This work was supported by the NOVEDAR Consolider-Ingenio 2010 Project (CSD2007-00055), the European Union (ROUTES-FP7-ENV-2010-265156) and the Spanish Government (CTM2011-24897, CTQ2009-11465, CGL2011-25401 and BES2012-054179). Sergi Astals is grateful to The University of Queensland for his 
fellowship (UQFEL1608109). The authors are also grateful to Miriam Peces from The

University of Queensland for her scientific contribution.

\section{References}

1. Agulló-Barceló, M., Oliva, F., Lucena, F., 2013. Alternative indicators for monitoring Cryptosporidium oocysts in reclaimed water. Environ. Sci. Pollut. Res. 20, 4448-4454. doi:10.1007/s11356-012-1400-4

2. APHA, 2005. Standard methods for the examination of water and wastewater. APHA-AWWA-WEF, Washington D.C.

3. Astals, S., Batstone, D.J., Tait, S., Jensen, P.D., 2015. Development and validation of a rapid test for anaerobic inhibition and toxicity. Water Res. 81, 208-215. doi:10.1016/j.watres.2015.05.063

4. Astals, S., Venegas, C., Peces, M., Jofre, J., Lucena, F., Mata-Álvarez, J., 2012. Balancing hygienization and anaerobic digestion of raw sewage sludge. Water Res. 46, 6218-6227. doi:10.1016/j.watres.2012.07.035

5. Bagge, E., Sahlström, L., Albihn, A., 2005. The effect of hygienic treatment on the microbial flora of biowaste at biogas plants. Water Res. 39, 4879-4886. doi:10.1016/j.watres.2005.03.016

6. Carrere, H., Antonopoulou, G., Affes, R., Passos, F., Battimelli, A., Lyberatos, G., Ferrer, I., 2016. Review of feedstock pretreatment strategies for improved anaerobic digestion: From lab-scale research to full-scale application. Bioresour. Technol. 199, 386-397. doi:10.1016/j.biortech.2015.09.007

7. Carrère, H., Dumas, C., Battimelli, A., Batstone, D.J., Delgenès, J.P., Steyer, J.P., Ferrer, I., 2010. Pretreatment methods to improve sludge anaerobic degradability: A review 183, 1-15. doi:10.1016/j.jhazmat.2010.06.129 
8. Chen, Y., Jiang, S., Yuan, H., Zhou, Q., Gu, G., 2007. Hydrolysis and acidification of waste activated sludge at different pHs. Water Res. 41, 683-689. doi:10.1016/j.watres.2006.07.030

9. Erkan, M., Sanin, F.D., 2013. Can sludge dewatering reactivate microorganisms in mesophilically digested anaerobic sludge? Case of belt filter versus centrifuge. Water Res. 47, 428-438. doi:10.1016/j.watres.2012.10.028

10. European Commission, 2000. Working Document on Sludge, 3rd Official Draft. European Commission, Brussels, Belgium. http://www.ewaonline.eu/comments.html (last accessed 25 October 2016).

11. Foladori, P., Laura, B., Gianni, A., Giuliano, Z., 2007. Effects of sonication on bacteria viability in wastewater treatment plants evaluated by flow cytometry Fecal indicators, wastewater and activated sludge. Water Res. 41, 235-243. doi:10.1016/j.watres.2006.08.021

12. Guzmán, C., Jofre, J., Montemayor, M., Lucena, F., 2007. Occurrence and levels of indicators and selected pathogens in different sludges and biosolids. J. Appl. Microbiol. 103, 2420-2429. doi:10.1111/j.1365-2672.2007.03487.x

13. Hill, V., Sobsey, M., 1998. Microbial indicator reductions in alternative treatment systems for swine wastewater. Water Sci. Technol. 38, 119-122. doi:10.1016/S0273-1223(98)00811-7

14. Jang, H.M., Cho, H.U., Park, S.K., Ha, J.H., Park, J.M., 2014. Influence of thermophilic aerobic digestion as a sludge pre-treatment and solids retention time ofmesophilic anaerobic digestion on the methane production, sludge digestion and microbial communities in a sequential digestion process. Water Res. 48, 1-14. doi:10.1016/j.watres.2013.06.041

15. Labbe, R.G., Huang, T.H., 1995. Generation times and modeling of enterotoxin- 
positive and enterotoxin-negative strains of Clostridium perfringens in laboratory media and ground Beef. J. Food Prot. 58, 1303-1306.

16. Lepeuple, A.S., Gaval, G., Jovic, M., Roubin, M.R. De, 2004. Horizontal Work Package 3, Task 6: Literature review on levels of pathogens and their abatement in sludges, soil and treated biowaste.

17. Marti, E., Monclús, H., Jofre, J., Rodriguez-Roda, I., Comas, J., Balcázar, J.L., 2011. Removal of microbial indicators from municipal wastewater by a membrane bioreactor (MBR). Bioresour. Technol. 102, 5004-5009. doi:10.1016/j.biortech.2011.01.068

18. McClane, B.A., 2003. Clostridium perfringens, in: Miliotis, M.D., Bier, J.W. (Eds.), International Handbook of Foodborne Pathogens. Marcel Dekker, Inc., New York (U.S.A.), Basel (Switzerland), pp. 91-104.

19. Park, S.K., Jang, H.M., Ha, J.H., Park, J.M., 2014. Sequential sludge digestion after diverse pre-treatment conditions: Sludge removal, methane production and microbial community changes. Bioresour. Technol. 162, 331-340. doi:10.1016/j.biortech.2014.03.152

20. Pascual-Benito, M., García-Aljaro, C., Casanovas-Massana, S., Blanch, A.R., Lucena, F., 2015. Effect of hygienization treatment on the recovery and/or regrowth of microbial indicators in sewage sludge. J. Appl. Microbiol. 118, 412418. doi:10.1111/jam.12708

21. Payment, P., Franco, E., 1993. Clostridium perfringens and somatic coliphages as indicators of the efficiency of drinking water treatment for viruses and protozoan cysts. Appl. Environ. Microbiol. 59, 2418-2424.

22. Peces, M., Astals, S., Mata-alvarez, J., 2015. Effect of moisture on pretreatment efficiency for anaerobic digestion of lignocellulosic substrates. Waste Manag. 46, 
189-196. doi:10.1016/j.wasman.2015.08.022

23. Rainisalo, A., Romantschuk, M., Kontro, M.H., 2011. Evolution of clostridia and streptomycetes in full-scale composting facilities and pilot drums equipped with on-line temperature monitoring and aeration. Bioresour. Technol. 102, 7975-7983. doi:10.1016/j.biortech.2011.05.087

24. Ruiz-Hernando, M., Cabanillas, E., Labanda, J., Llorens, J., 2015. Ultrasound, thermal and alkali treatments affect extracellular polymeric substances (EPSs) and improve waste activated sludge dewatering. Process Biochem. 50, 438-446. doi:10.1016/j.procbio.2015.01.001

25. Ruiz-Hernando, M., Martín-Díaz, J., Labanda, J., Mata-Alvarez, J., Llorens, J., Lucena, F., Astals, S., 2014. Effect of ultrasound, low-temperature thermal and alkali pre-treatments on waste activated sludge rheology, hygienization and methane potential. Water Res. 61,119-129. doi:10.1016/j.watres.2014.05.012

26. Sahlström, L., Aspan, A., Bagge, E., Danielsson-Tham, M.L., Albihn, A., 2004. Bacterial pathogen incidences in sludge from Swedish sewage treatment plants. Water Res. 38, 1989-1994. doi:10.1016/j.watres.2004.01.031

27. Salsali, H., Parker, W.J., Sattar, S.A., 2008. The effect of volatile fatty acids on the inactivation of Clostridium perfringens in anaerobic digestion. World J. Microbiol. Biotechnol. 24, 659-665. doi:10.1007/s11274-007-9514-4

28. Shah, F.A., Mahmood, Q., Shah, M.M., Pervez, A., Asad, S.A., 2014. Review article. Microbial ecology of anaerobic digesters: The key players of anaerobiosis. Sci. World J. 183752, 1-21. doi:10.1155/2014/183752

29. Stiborova, H., Wolfram, J., Demnerova, K., Macek, T., Uhlik, O., 2015. Bacterial community structure in treated sewage sludge with mesophilic and thermophilic anaerobic digestion. Folia Microbiol. (Praha). 60, 531-539. doi:10.1007/s12223- 
015-0396-9

30. The Council of European Communities, 1986. Council Directive 86/278/EEC on Protection of the Environment, and in particular of the soil, when sewage sludge is used in agriculture. Off. J. Eur. Communities 4, 6-12.

31. Tian, Z., Zhang, Y., Li, Y., Chi, Y., Yang, M., 2015. Rapid establishment of thermophilic anaerobic microbial community during the one-step startup of thermophilic anaerobic digestion from a mesophilic digester. Water Res. 69, 9-19. doi:10.1016/j.watres.2014.11.001

32. US Environmental Protection Agency, 2003. Environmental Regulations and Technology Control of Pathogens and Vector Attraction in Sewage Sludge Control of Pathogens and Vector Attraction, Environmental Protection. doi:10.1016/S0015-1882(99)80035-4

33. Warnes, S.L., Keevil, C.W., 2004. Horizontal Work Package 3, Task 4: Desk studies on feasibility of horizontal standard rapid methods for detection of Clostridium perfringens and enterococci in Sludges, Soil, Soil Improvers, Growing Media and Biowastes.

34. Wéry, N., Lhoutellier, C., Ducray, F., Delgenès, J.P., Godon, J.J., 2008. Behaviour of pathogenic and indicator bacteria during urban wastewater treatment and sludge composting, as revealed by quantitative PCR. Water Res. 42, 53-62. doi:10.1016/j.watres.2007.06.048

35. Yuan, Y., Wang, S., Liu, Y., Li, B., Wang, B., Peng, Y., 2015. Long-term effect of $\mathrm{pH}$ on short-chain fatty acids accumulation and microbial community in sludge fermentation systems. Bioresour. Technol. 197, 56-63.

doi:10.1016/j.biortech.2015.08.025 


\section{Figure captions}

Table 1. $\mathrm{pH}$ measurements during GLY treatment in comparison with $35.3-\mathrm{NaOH}$.

Table 2. Sulfite-reducing clostridia and E. coli data for WWTP digestion, raw wastewater and human feces. Mean \pm standard deviation. Data in $\log _{10}(\mathrm{CFU} / \mathrm{g} \text { TS })^{\mathrm{a}}$ or $\log _{10}(\mathrm{CFU} / \mathrm{mL})^{\mathrm{b}}$. Analyses were performed twice.

Fig. 1. Effect of pre-treatments on sulfite-reducing clostridia concentrations. Error bars represent standard deviation.

Fig. 2. Variations in sulfite-reducing clostridia levels over $24 \mathrm{~h}$ in (a) untreated WAS, and (b) 35.3-NaOH treated WAS. Error bars represent standard deviation.

Fig. 3. Effect of high energy ultrasound treatments (40,000-US and 60,000-US) on sulfite-reducing clostridia and E. coli concentrations. Error bars represent standard deviation.

Fig. 4. Effect of digestion on sulfite-reducing clostridia concentrations after 0,15 and 35 days: (a) Untreated, (b) 35.3- $\mathrm{NaOH}$, (c) 157- $\mathrm{NaOH}$, (d) 27,000-US. Error bars represent standard deviation. 


\section{Tables and Figures}

\section{Table 1}

$\mathrm{pH}$ measurements during GLY treatment in comparison with 35.3- $\mathrm{NaOH}$.

\begin{tabular}{|c|c|c|c|c|c|c|c|c|c|c|c|c|c|c|c|}
\hline & \multicolumn{15}{|c|}{ Iime (h) } \\
\hline & 0 & 1 & 2 & 3 & 4 & 5 & 6 & 7 & 8 & 9 & 10 & 11 & 12 & 13 & 24 \\
\hline Untreated & 7.15 & 6.94 & 6.95 & 6.93 & 6.93 & 6.94 & 6.96 & 6.98 & 7.00 & 7.00 & 7.00 & 7.06 & 7.06 & 7.06 & 6.96 \\
\hline GLY & 10.50 & 10.05 & 8.99 & 8.51 & 8.00 & 7.98 & 7.98 & 7.51 & 7.47 & 7.46 & 7.46 & 7.45 & 7.42 & 7.02 & 7.01 \\
\hline $35.3-\mathrm{NaOH}$ & 10.35 & & & & 8.25 & & & & 7.56 & & & & & & 6.92 \\
\hline
\end{tabular}


Table 2

Sulfite-reducing clostridia and E. coli data for WWTP digestion, raw wastewater and human feces. Mean \pm standard deviation. Data in $\log _{10}(\mathrm{CFU} / \mathrm{g} \text { TS })^{\mathrm{a}}$ or $\log _{10}(\mathrm{CFU} / \mathrm{mL})^{\mathrm{b}}$. Analyses were performed twice.

\begin{tabular}{ccccccccc} 
& \multicolumn{2}{c}{ Human feces } & \multicolumn{3}{c}{ WWTP $_{1}$} \\
\cline { 2 - 9 } & $\mathrm{A}^{\mathrm{a}}$ & $\mathrm{B}^{\mathrm{a}}$ & $\begin{array}{c}\text { Raw } \\
\text { wastewater }\end{array}$ & $\begin{array}{c}\text { Sludge } \\
\text { before } \\
\mathrm{AD}^{\mathrm{a}}\end{array}$ & $\begin{array}{c}\text { Sludge } \\
\text { after } \\
\mathrm{AD}^{\mathrm{a}}\end{array}$ & $\begin{array}{c}\text { Raw } \\
\text { wastewater }\end{array}$ & $\begin{array}{c}\text { Sludge } \\
\text { before } \\
\text { AD }^{\mathrm{a}}\end{array}$ & $\begin{array}{c}\text { Sludge } \\
\text { after } \\
\mathrm{AD}^{\mathrm{a}}\end{array}$ \\
\hline $\mathrm{TSRC}$ & $4.14 \pm 0.02$ & $4.31 \pm 0.21$ & $3.35 \pm 0.10$ & $7.23 \pm 0.03$ & $7.19 \pm 0.14$ & $3.34 \pm 0.02$ & $6.75 \pm 0.32$ & $7.08 \pm 0.11$ \\
\hline SSRC & $3.73 \pm 0.13$ & $4.48 \pm 0.17$ & $3.44 \pm 0.06$ & $6.78 \pm 0.07$ & $6.75 \pm 0.05$ & $3.43 \pm 0.04$ & $6.77 \pm 0.05$ & $7.04 \pm 0.19$ \\
\hline E. coli & $6.22 \pm 0.13$ & $6.49 \pm 0.18$ & $4.26 \pm 0.04$ & $6.50 \pm 0.04$ & $5.40 \pm 0.01$ & $4.73 \pm 0.05$ & $7.35 \pm 0.06$ & $4.79 \pm 0.04$ \\
\hline $\begin{array}{c}\text { SSRC/E. } \\
\text { coli }\end{array}$ & 0.60 & 0.69 & 0.81 & 1.04 & 1.25 & 0.73 & 0.92 & 1.47 \\
\hline
\end{tabular}


Figure 1:

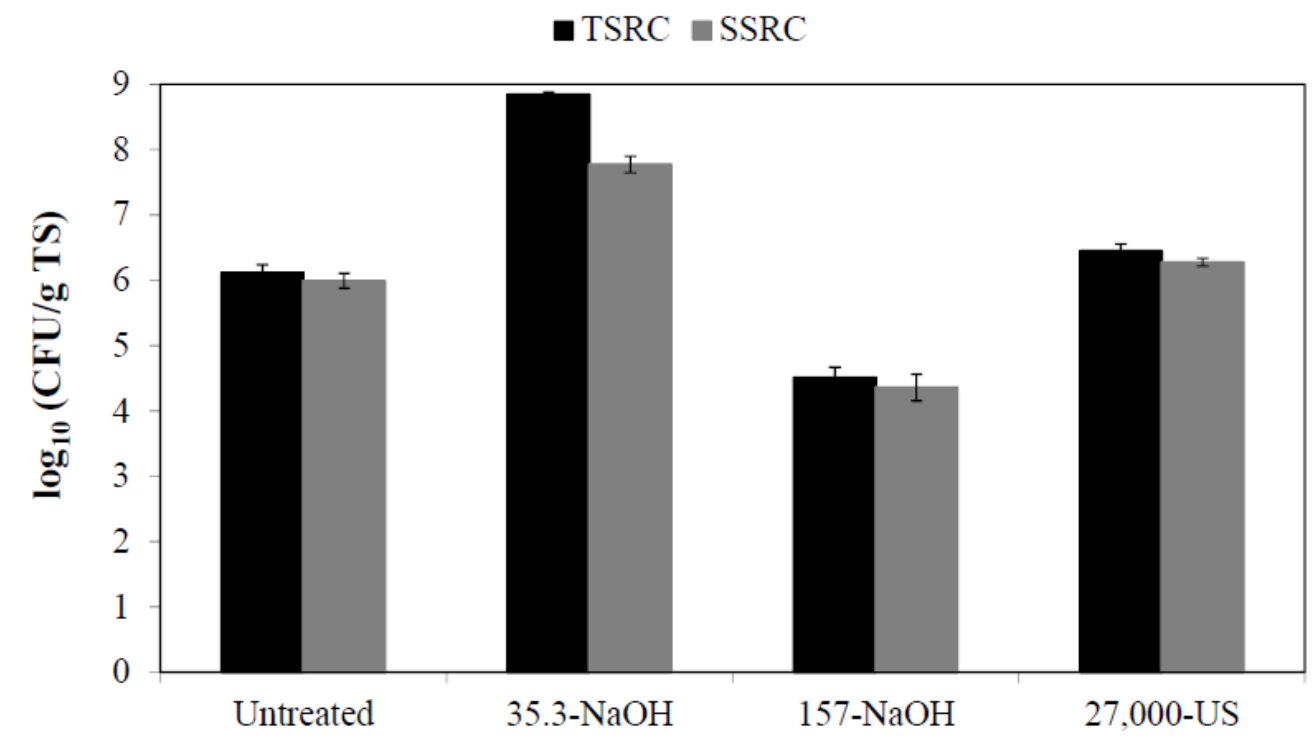


Figure 2:

(a)

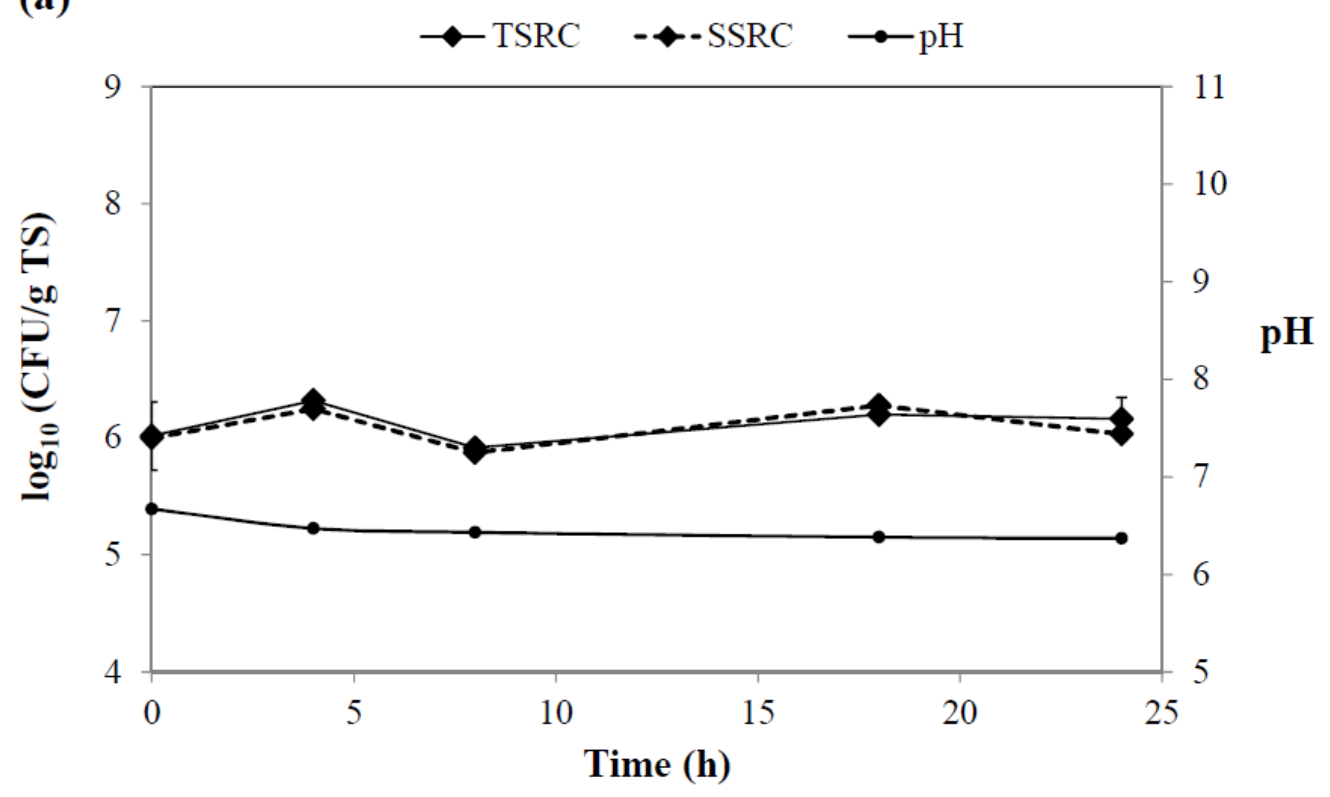

(b)

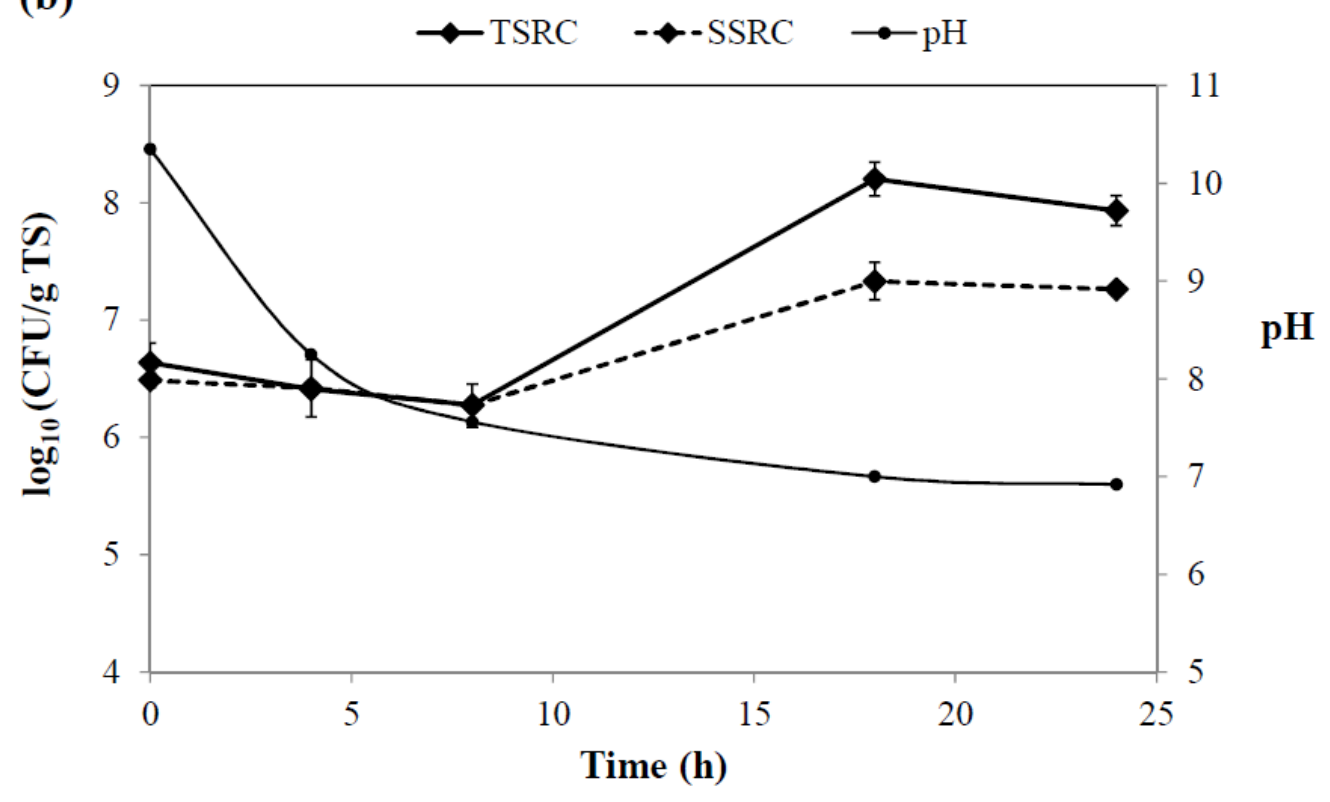


Figure 3:

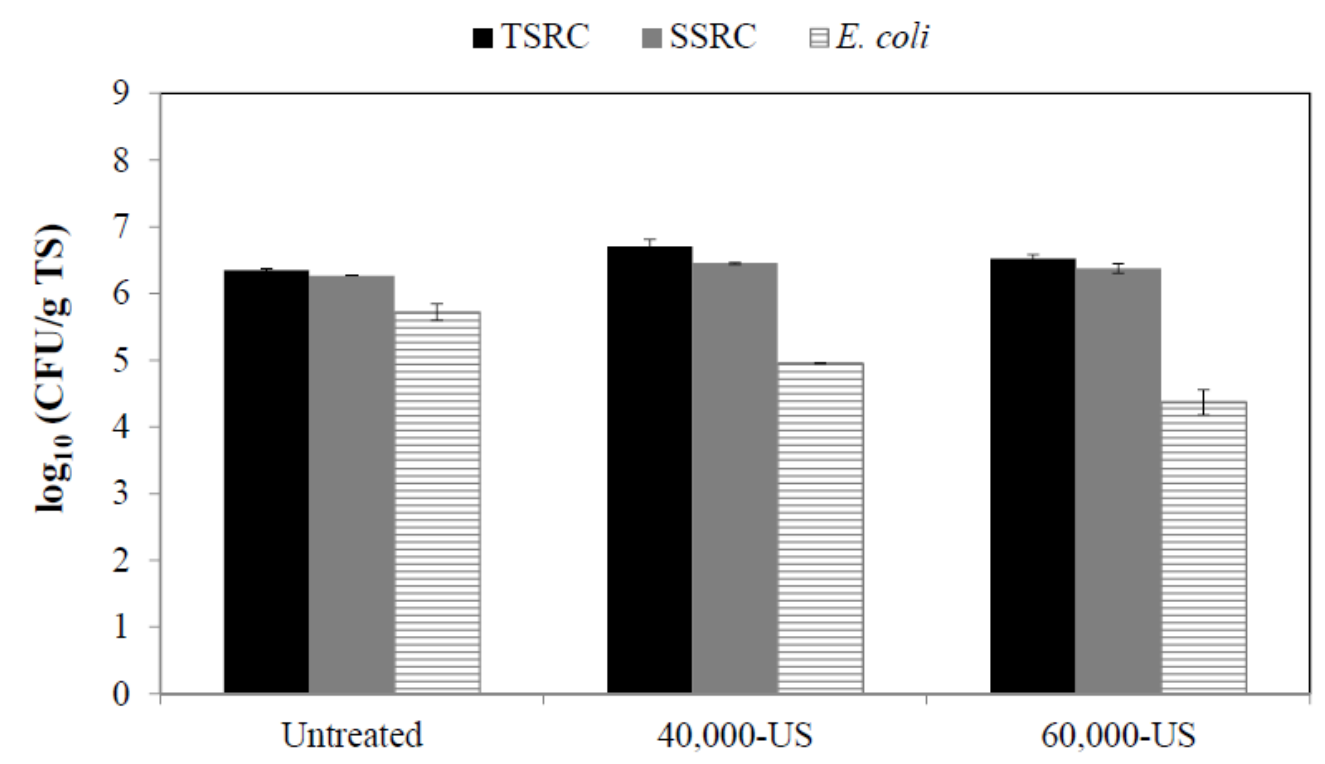


Figure 4:
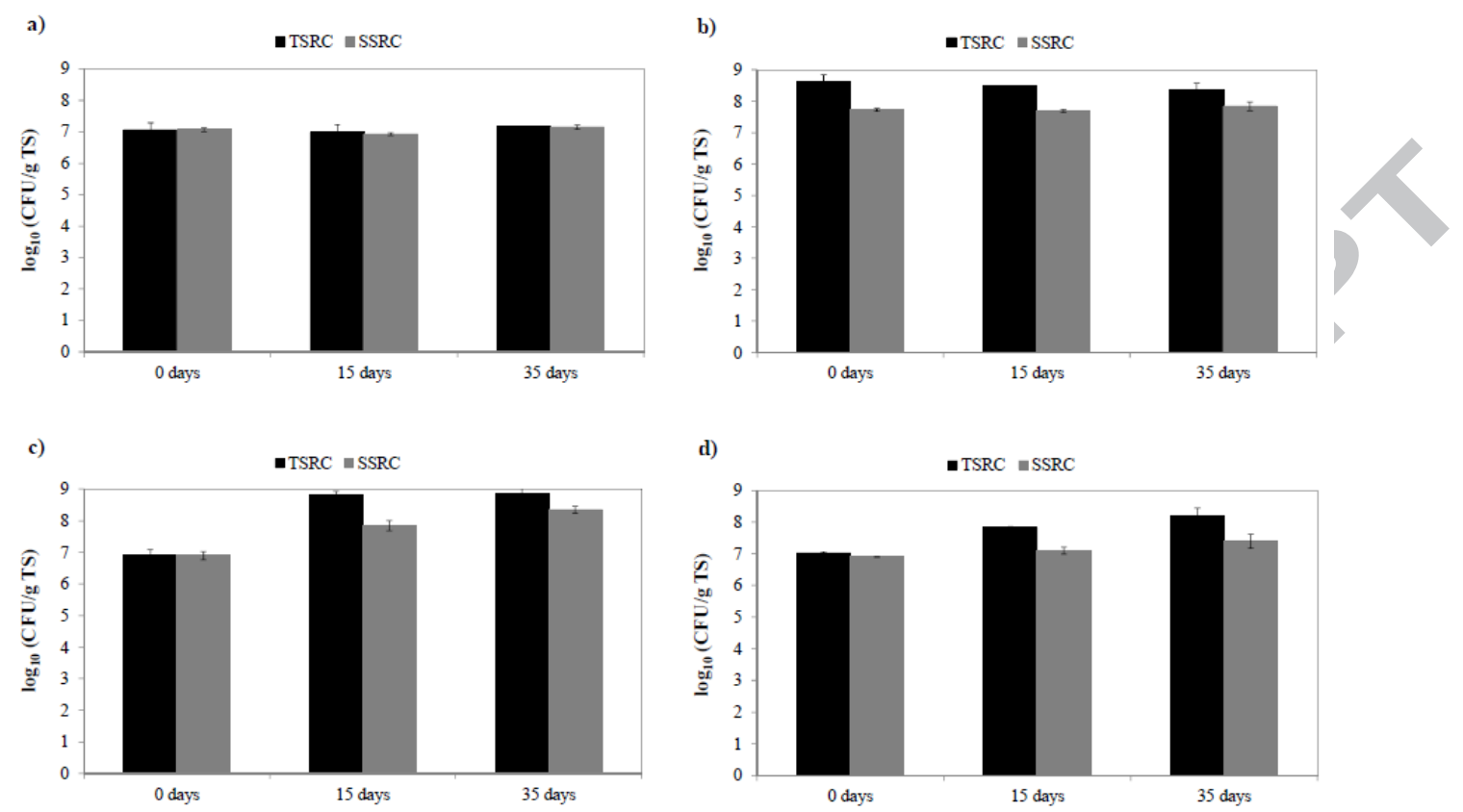


\section{Highlights}

- Clostridia and E. coli were monitored during sewage sludge anaerobic digestion

- Results question the usefulness of clostridia as sewage sludge treatment indicators

- Alkali pre-treatment (35.3 g NaOH/kg TS; 24h) increased clostridia levels

- Clostridia also increased after digesting $\mathrm{NaOH}$ or ultrasound pre-treated sludge

- E. coli levels did not increase under any of the tested conditions 


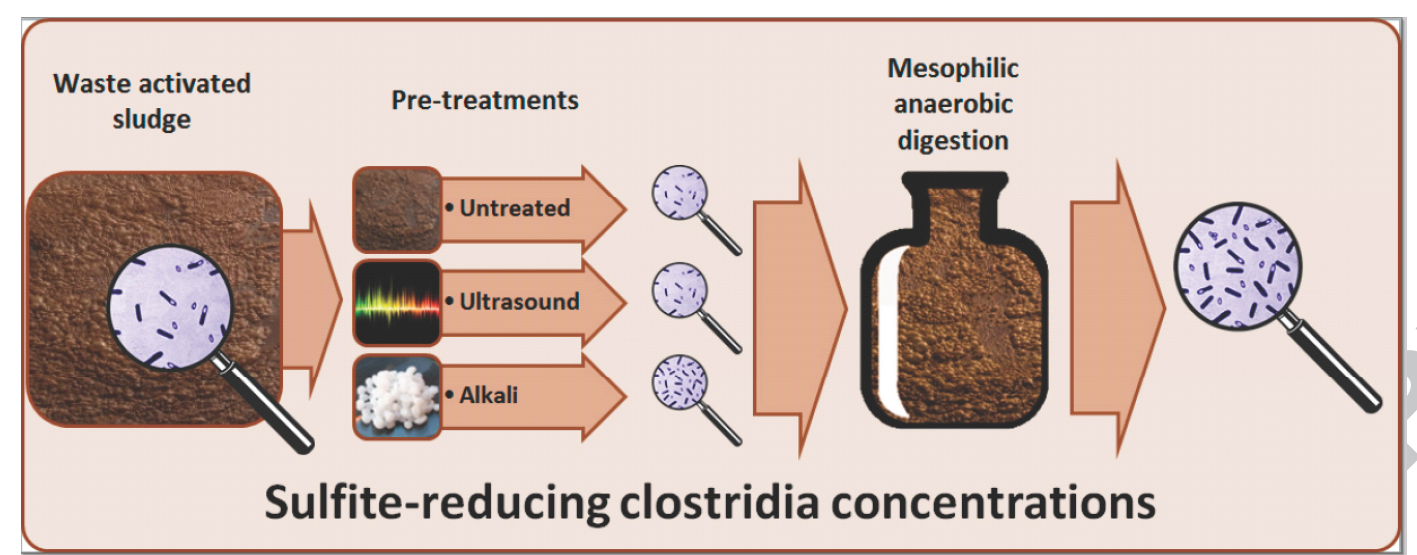

